\title{
Gender differences in cancer-related distress in Japan: a retrospective observation study
}

\author{
Atsuko Koyama*, Hiromichi Matsuoka, Yoichi Ohtake, Chihiro Makimura, Kiyohiro Sakai, Ryo Sakamoto
} and Masahiko Murata

\begin{abstract}
Background: Cancer care is currently the most important medical issue in Japan. Total pain of cancer patients consists of a combination of four factors: physical, psychological, social distress, and spiritual pain. Previous studies showed female cancer patients ask for more psychological support and seem to suffer different types of distress compared with male patients, for example, appearance-related symptoms. However, other factors of cancer distress related to gender have not been defined comprehensively. The aim of this study is to clarify the gender differences in cancer distress types in order to elucidate the measures that should be taken in Japan to improve the quality of whole cancer care based on gender-based medicine.

Methods: The data of new patients who had visited the psycho-oncology outpatient service of Kinki University Hospital during the period of May 2013 to October 2015 were collected. Demographic factors and all assessed items were extracted from the patients' medical charts retrospectively. Based on an inquiry of cancer patients in 2010, each item representing the four factors of "total pain" of cancer patients was chosen, i.e., physical distress (pain, changes in appearance), psychological distress (anxiety, depression), social distress (family problems, job-related problems), and spiritual pain; together with sexuality issues, and answers were analyzed. Hospital Anxiety Depression Scale (HADS) was used for the assessment of psychological distress. Chi-square test and Fisher's exact test were performed for gender differences in the cancer distress types. Pearson's analysis and multiple logistic regression analysis were performed for the association of gender with each item.
\end{abstract}

Results: The data of 101 cancer patients were analyzed and there were more female patients than male patients (female: male ratio $=71: 30$ ). Female cancer patients were more likely to suffer from psycho-social issues such as changes in appearance, family problems and sexuality issues than male patients, and male patients were more likely to have spiritual pain.

Conclusions: There were gender differences in the distress types of cancer patients. In order to improve the quality of whole cancer care, more intensive intervention by medical professionals and social support is needed from the viewpoint of gender-based medicine and psycho-oncology.

Keywords: Cancer, Distress, Total pain, Gender differences, Gender-based medicine, Psycho-oncology

\footnotetext{
* Correspondence: a-koyama@med.kindai.ac.jp

Department of Psychosomatic Medicine, Kinki University, Faculty of Medicine,

377-2, Ohno-higashi, Osakasayama City, Osaka 589-8511, Japan
} 


\section{Background}

For the last few decades, the prevalence of cancer has been increasing in Japan. Cancer has been the leading cause of death among Japanese people since 1981 and approximately one third of Japan's population will die of cancer [1]. Thus, cancer care is currently the most important medical issue in Japan. In order to improve the quality of life of both cancer patients and their families, the Japanese government developed a plan for cancer care that has been used since 2004. The plan is revised every 5 years. The Cancer Control Act [2] was enforced in 2007 and states the importance of psychosocial care, as well as physical care for cancer patients. The complicated distress of cancer patients is called "total pain", which was advocated by Cicely Saunders who created St. Christopher's Hospice in England [3]. Total pain of cancer patients consists of a combination of four factors: physical, psychological, social distress, and spiritual pain.

Previous studies showed that more than $30 \%$ of cancer patients have a need for psychosocial support [4-7] and that female patients requested more assistance [8]. There were role and gender differences regarding psychological distress and quality of life when dealing with cancer. Not only female cancer patients, but also female partners of male cancer patients, had psychological distress and a low quality of life $[9,10]$. In addition, female cancer patients seem to suffer different types of distress compared with male patients. For example, women suffered from more appearance-related symptoms and distress resulting from chemotherapy than men [11]. However, other factors of cancer distress related to gender have not been defined comprehensively.

The aim of this study is to clarify the differences in distress types between female and male cancer patients in order to elucidate the measures that should be taken in Japan to improve the quality of whole cancer care from the viewpoint of gender-based medicine and psycho-oncology.

\section{Methods}

\section{Patients}

The department of psychosomatic medicine, Kinki University Faculty of Medicine operates a specific outpatient service for cancer patients. The data of new patients who had visited the specific outpatient service for psycho-oncology during the period of April 2013 to October 2015 were collected. All patients were at least 16 years old.

\section{Design and settings}

All patients filled out a medical questionnaire and a semiconducted interview was performed asking for more details based on the questionnaire during their first visit to our department, with the answers recorded in their medical charts.

All the items assessed were extracted from the patients' medical charts retrospectively. Demographic factors such as age, gender, cancer site, period of time after first diagnosis or recurrence, and profiles of therapies before the assessment (operation, chemotherapy, radiation, hormonal therapy) were extracted from the medical charts. Based on the inquiry of cancer patients in 2010 [12], each item representing the four factors of "total pain" of cancer patients was chosen: Physical distress (pain, changes in appearance), psychological distress (anxiety, depression), social distress (family problems, job-related problems), and spiritual pain; together with sexuality issues and answers were analyzed. All items were assessed with a binary scale: 'yes' or 'no'. In order to minimize an assessment bias among researchers, the criteria for designating an item as 'yes' is indicated in Fig. 1. The items of "pain" included both cancer and non-cancer pain, such as headache and abdominal pain, and were assessed using 'yes' or 'no'. Examples of questions are: "Do you have cancer-related pain such as bone metastasis or non-cancer related pain such as tension headache? Which best describes your condition on the Numeric Rating Scale (NRS) (0-10) ?" The patients with some pain, except for those who chose 0 in NRS, were judged as 'yes'. The items of "changes in appearance" included mastectomy, alopetia due to chemotherapy, facial disfigurement of the head and neck, and colon or bladder stoma. The items of "anxiety and depression" were assessed by the Hospital Anxiety Depression Scale (HADS) [13], which contains 14 questions and 4 degrees $(0,1,2,3)$ in each answer. All of the patients completed this psychological test for the assessment of psychological distress during their first visit to our department. In HADS, a cut-off score of 11 was adopted in this study to determine that patients were considered to be in an anxiety and/or depressive state respectively. The items of "family problems" included conflicts and/or changes in relationship with the patients' parents, children, or partner. Examples of questions were: "Do you have any problems related to your family? With whom? What is your family member's reaction?" Responses such as "I cannot take care of my parents anymore.”, "I am concerned about my children's future.", or "My partner is avoiding conversations about cancer and/or sex with me." in the medical charts were counted as family problems. The items of "job-related problems" contained dismissal or suspension from a job, decreasing income, and difficulties in a relationship with co-workers. Spiritual pain could be described as a feeling of meaninglessness of life, loss of identity and worthlessness of living [14]. Examples of questions were: "Do you have any distress derived from loss of the future, loss of 
Distress factors

1. Physical distress

1) Pain

cancer-related pain (e.g. bone metastasis)

non-cancer pain (e.g. tension headache)

2) Changes in appearance

mastectomy

alopecia

facial disfigurement

colon / bladder stoma

2. Psychological distress

1) Anxiety (HADS-A $\geq 11)$

2) Depression (HADS-D $\geq 11$ )

3. Social distress

1) Family problems (conflict or changes in relationship with parents, children, partner)

2) Job-related problems

dismissal/suspension

decrease in income

relationship with co-workers

4. Spiritual pain

1) Meaninglessness of life (e.g. "therapy or any other efforts are meaningless since I am dying.", "My life is empty.", "I do not have a vivid sensation of living.")

2) Loss of identity (e.g. "I am lonely.", "No one understands my real feelings."

3) Worthlessness of living (e.g. "My presence is a nuisance for my family and friends so I want to die soon.")

5. Sexuality issues

1) Sexual dysfunction

2) Infertility

3) Decrease in libido

Fig. 1 The criteria of items of cancer distress factors. Based on the inquiry of cancer patients in 2010 [12], each item representing the four factors of "total pain" of cancer patients, i.e., physical distress (pain, changes in appearance), psychological distress (anxiety, depression), social distress (family problems, job-related problems), and spiritual pain; along with sexuality issues, were chosen to be used in this study. All items were assessed using a binary scale: 'yes' or 'no'. The criteria for designating an item as 'yes' is indicated in Fig. 1

others, and loss of autonomy?" Responses such as "therapy and other efforts are meaningless since I am dying.", "My life is empty.", "I do not have a vivid sensation of living.", "I am lonely.", "No one understands my real feelings.", or "My presence is a nuisance for my family and friends so I want to die soon." in medical charts were counted as spiritual pain. Sexuality issues contained sexual dysfunction, infertility and decreasing libido.

\section{Consent}

Our study was approved by the ethical committee of Kinki University of Medicine (No 27-185). Since this study was a retrospective observation study analyzing data extracted during routine clinical practice, written informed consent was not necessary according to the ethics guidelines for epidemiological studies developed by the Japanese Ministry of Labor, Health, and Welfare. We paid attention not to infringe on patient privacy as much as possible and publicly displayed information regarding this study on the homepage of our department (http:// www.kindai-psychosomatics.com/) so that those unwilling to participate could contact us to refuse participation.

\section{Measurements}

This was a mixed-method statistical study with cancer patients. Chi-square test and Fisher's exact test were performed to provide a preliminary comparison of the cancer distress types of male and female patients. Analysis to determine the correlation coefficient between each item of distress was performed using Pearson's 
analysis. The index for each item is yes $=1$ and no $=0$. For gender it is male $=1$, female $=0$. Multiple logistic regression analysis was performed to identify the factors associated with gender, using each item of a distress type as an independent variable. All statistical analyses were conducted using SPSS software (version 19.0; SPSS Japan Inc., Tokyo).

\section{Results}

\section{Patient characteristics}

Detailed demographic and clinical characteristics of the patients are listed in Table 1. The data of 101 cancer patients were analyzed and the most common cancer site was breast cancer. This table demonstrated that there were more female patients than male patients (female: male ratio $=71: 30$ ). Characteristics were assessed at the time of the first visit to our department. Although there were no significant differences, more than half of the female patients came to our psycho-oncology outpatient service within 3 months after diagnosis. Conversely, more than half of the male patients came after 3 months. Patients

Table 1 Demographic and clinical characteristics of patients

\begin{tabular}{|c|c|c|}
\hline & Female & Male \\
\hline$N$ & 71 & 30 \\
\hline Age (years) & $55.7 \pm 12.5$ & $64.1 \pm 11.8$ \\
\hline \multicolumn{3}{|l|}{ Primary cancer site } \\
\hline Breast & 50 & 0 \\
\hline Digestive organ & 4 & 14 \\
\hline Lung & 6 & 6 \\
\hline Head \& Neck & 3 & 5 \\
\hline Gynecological organ & 5 & 0 \\
\hline Urological organ & 1 & 3 \\
\hline Blood & 0 & 2 \\
\hline Others & 1 & 1 \\
\hline Recurrence & 18 & 11 \\
\hline \multicolumn{3}{|l|}{ Periods after diagnosis ${ }^{a}$} \\
\hline$<1$ month & 8 & 2 \\
\hline$\geq 1-3$ months & 39 & 7 \\
\hline$\geq 3-6$ months & 21 & 13 \\
\hline$\geq 6$ months & 3 & 8 \\
\hline \multicolumn{3}{|l|}{ Profiles of therapies ${ }^{b}$} \\
\hline None & 8 & 1 \\
\hline Operation & 54 & 23 \\
\hline Chemotherapy & 48 & 24 \\
\hline Radiation & 31 & 8 \\
\hline Hormonal therapy & 33 & 1 \\
\hline
\end{tabular}

Data are shown as a number and Age is described as mean \pm SD

a Periods after first diagnosis or recurrence

${ }^{\mathrm{b}}$ The sum exceeds the patient total number because one patient experienced additional therapy who had not undergone therapy came to our department just after diagnosis. Approximately two thirds of both female and male patients had a history of operation and chemotherapy, however, female patients experienced hormonal therapy much more than male patients.

\section{The gender differences in the cancer patient distress types}

In the chi-square test and Fisher's exact test shown in Table 2, female patients were more likely to be suffering from psycho-social issues such as changes in appearance, family problems, and sexuality issues than male patients. Male patients were more likely to have spiritual pain.

The results of the correlation matrix table are shown in Table 3. Changes in appearance, family problems, spiritual pain, and sexuality issues were significantly correlated with gender. Using yes $=1$, no $=0$, male $=1$, and female $=0$, a Pearson's correlation coefficient value of -0.202 between gender and changes in appearance showed that female patients were more likely to be suffering from changes in appearance $(p<0.05)$. Similarly, female patients were more likely to be suffering from family problems $(p<0.01)$ and sexuality issues $(p<0.05)$. Male patients were more likely to be suffering from spiritual pain $(p<0.05)$. Changes in appearance and sexuality issues $(p<0.05)$, anxiety and job-related problems $(p<0.01)$, depression and family problems $(p<0.05)$, and family problems and sexuality issues $(P<0.05)$ were correlated with each other in this model. No other correlations were found.

In the multiple logistic regression model, family problems were significantly associated with gender (odds ratio, $0.27 ; C I_{95}=0.10-0.71 ; p<0.01$ ), as was spiritual pain (odds ratio, $3.35 ; C I_{95}=1.27-8.83 ; p<0.05$ ). No other associations were found.

\section{Discussion}

\section{Patient characteristics}

More than twice the number of female than male cancer patients had asked for psycho-oncological support and come to our department. One of the reasons for this feature seems to be that breast cancer patients make up about $50 \%$ of the total patients in this study. The reason female patients experienced hormonal therapy much more than male patients was because of the high number of breast cancer patients.

\section{Gender differences of cancer distress}

The chi-square and Fisher's exact tests showed an association of female patients with changes in appearance, family problems, and sexuality issues and of male patients with spiritual pain. Pearson's analysis showed the same results and changes in appearance and sexuality issues, anxiety and job-related problems, depression 
Table 2 The association of gender and distress type

\begin{tabular}{llclcc}
\hline & Male $(N=30)$ & Percent & Female $(N=71)$ & Percent & $p$ Value \\
\hline Pain & 17 & 56.7 & 31 & 43.7 & 0.2317 \\
Changes in appearance & 2 & 0.7 & 17 & 23.9 & 76.1 \\
Anxiety & 23 & 76.7 & 54 & 38.0 & $0.0423^{*}$ \\
Depressive mood & 12 & 40.0 & 27 & 69.0 & 0.8525 \\
Family problems & 11 & 36.7 & 49 & 16 & 22.5 \\
Job-related problems & 10 & 33.3 & 16 & 22.5 & $0.0025^{* *}$ \\
Spiritual pain & 15 & 50.0 & 13 & 18.3 & 0.2567 \\
Sexuality issues & 1 & 3.3 & & $0.062^{* *}$ \\
\hline
\end{tabular}

Results of chi-square test/Fisher's exact test

${ }^{*} p<0.05$

${ }^{* *} p<0.01$

and family problems, and family problems and sexuality issues were correlated. However, in the multiple logistic regression model, only family problems and spiritual pain were significantly associated with gender.

\section{Changes in appearance}

Changes in appearance cause serious distress for cancer patients, which is manifested as five D's: Death; Dependence on family or medical staff; Disfigurement; Disruption of life, purpose or desire; and Disability [15]. As for women, it is imaginable that cosmetic problems easily affect their psychological state and quality of life. Previous studies showed that many breast cancer patients suffer from psychological distress due to adverse effects and lifelong physical disfigurement [16]. Head and neck cancer patients also face functional impairment and disfigurement caused by cancer and/or its treatment and have psychosocial difficulties such as depressed mood [17]. Colon and bladder stoma is another distress for cancer patients. Not only irreversible changes, but also temporary changes in appearance such as chemotherapyinduced alopecia, also give a psychological burden to cancer patients $[18,19]$. Moreover, these changes in appearance might relate to sexuality issues [20, 21], and there was a significant correlation in Pearson's analysis in this study.

Cancer patients are often reluctant to discuss these issues with their healthcare team, so more effective screening scales [22, 23], information, education [24] and care are needed [11]. Previous studies showed that social support and self-efficacy mediate the relationship between social distress and emotional distress in head and neck cancer patients with disfigurements $[25,26]$.

\section{Sexuality issues}

Sexual dysfunction is one of the most common and distressing consequences of cancer treatment [27] and this often occurs in patients with breast cancer and gynecological cancers [28]. The distress of sexuality issues consists of the complicated combination of physical effects of cancer treatment, women's intrapsychic experiences of changes to sexuality and her relationship with her partner, and the role of gendered discourse [29]. In this study, the number of gynecological cancer patients was small, but they seemed to suffer the same type of problems as those of breast cancer patients.

Considering the combined factors of sexuality issues, in order to improve the sexual dysfunction of breast cancer patients following mastectomy, breast reconstruction and a reciprocal communication style were important for couples' coping [30]. The correlation between sexuality issues and family problems was also significant in Pearson's analysis in this study. Several Japanese women hesitate to talk about sexual problems with their partners. In Japanese culture, there exists a way of thinking that breasts and the uterus are symbols of femininity. When women have a mastectomy or hysterectomy, they seem to think of this situation as the loss of femininity and may lose self-esteem. However, this tendency is not only seen in Japan, but is also common in other countries [31]. Cancer patients need more open-minded discussion and support from their partners and healthcare professionals [32]. The approach from nurses [33] and web-based support groups might be feasible due to their anonymity [34], and health care providers should give more distress screening, information and treatment interventions to cancer patients with sexuality distress $[35,36]$.

\section{Family problems}

Female cancer patients had more psycho-social distress regarding family problems than males.

Among family members, the relationship with a partner is crucial. For example, the provision or withdrawal of a partners' support can have a considerable impact on the psychosocial adjustment of female colorectal cancer patients with ostomies [37]. Furthermore, the relationship with their partner is related to their sexuality. Previous studies showed that the psychosocial distress of 
Table 3 The correlation between each distress type

\begin{tabular}{|c|c|c|c|c|c|c|c|c|c|c|}
\hline & & Gender & Pain & $\begin{array}{l}\text { Changes in } \\
\text { appearance }\end{array}$ & Anxiety & Depression & $\begin{array}{l}\text { Family } \\
\text { problems }\end{array}$ & $\begin{array}{l}\text { Job-related } \\
\text { problems }\end{array}$ & $\begin{array}{l}\text { Spiritual } \\
\text { pain }\end{array}$ & $\begin{array}{l}\text { Sexuality } \\
\text { issues }\end{array}$ \\
\hline \multirow[t]{3}{*}{ Gender } & Pearson's correlation coefficient & & & & & & & & & \\
\hline & $\begin{array}{l}\text { Significance probability } \\
\text { (both sides) }\end{array}$ & & & & & & & & & \\
\hline & $N$ & 101 & & & & & & & & \\
\hline \multirow[t]{3}{*}{ Pain } & Pearson's correlation coefficient & 0.119 & & & & & & & & \\
\hline & $\begin{array}{l}\text { Significance probability } \\
\text { (both sides) }\end{array}$ & 0.236 & & & & & & & & \\
\hline & $N$ & 101 & 101 & & & & & & & \\
\hline \multirow[t]{3}{*}{$\begin{array}{l}\text { Changes in } \\
\text { appearance }\end{array}$} & $\begin{array}{l}\text { Pearson's correlation } \\
\text { coefficient }\end{array}$ & -0.202 & 0.049 & & & & & & & \\
\hline & $\begin{array}{l}\text { Significance probability } \\
\text { (both sides) }\end{array}$ & $0.043^{a}$ & 0.625 & & & & & & & \\
\hline & $N$ & 101 & 101 & 101 & & & & & & \\
\hline \multirow[t]{3}{*}{ Anxiety } & $\begin{array}{l}\text { Pearson's correlation } \\
\text { coefficient }\end{array}$ & 0.007 & -0.028 & 0.150 & & & & & & \\
\hline & $\begin{array}{l}\text { Significance probability } \\
\text { (both sides) }\end{array}$ & 0.948 & 0.784 & 0.135 & & & & & & \\
\hline & $N$ & 101 & 101 & 101 & 101 & & & & & \\
\hline \multirow[t]{3}{*}{ Depression } & $\begin{array}{l}\text { Pearson's correlation } \\
\text { coefficient }\end{array}$ & 0.019 & 0.019 & -0.700 & 0.108 & & & & & \\
\hline & $\begin{array}{l}\text { Significance probability } \\
\text { (both sides) }\end{array}$ & 0.854 & 0.851 & 0.489 & 0.281 & & & & & \\
\hline & $N$ & 101 & 101 & 101 & 101 & 101 & & & & \\
\hline \multirow[t]{3}{*}{ Family problems } & $\begin{array}{l}\text { Pearson's correlation } \\
\text { coefficient }\end{array}$ & -0.301 & -0.021 & 0.140 & -0.083 & 0.200 & & & & \\
\hline & $\begin{array}{l}\text { Significance probability } \\
\text { (both sides) }\end{array}$ & $0.002^{b}$ & 0.837 & 0.163 & 0.412 & $0.045^{\mathrm{a}}$ & & & & \\
\hline & $N$ & 101 & 101 & 101 & 101 & 101 & 101 & & & \\
\hline \multirow[t]{3}{*}{$\begin{array}{l}\text { Job-related } \\
\text { problems }\end{array}$} & $\begin{array}{l}\text { Pearson's correlation } \\
\text { coefficient }\end{array}$ & 0.113 & 0.029 & 0.180 & 0.276 & 0.184 & 0.026 & & & \\
\hline & $\begin{array}{l}\text { Significance probability } \\
\text { (both sides) }\end{array}$ & 0.261 & 0.772 & 0.071 & $0.005^{b}$ & 0.065 & 0.800 & & & \\
\hline & $N$ & 101 & 101 & 101 & 101 & 101 & 101 & 101 & & \\
\hline \multirow[t]{3}{*}{ Spiritual pain } & $\begin{array}{l}\text { Pearson's correlation } \\
\text { coefficient }\end{array}$ & 0.272 & 0.097 & -0.046 & 0.119 & 0.134 & -0.018 & 0.148 & & \\
\hline & $\begin{array}{l}\text { Significance probability } \\
\text { (both sides) }\end{array}$ & $0.006^{b}$ & 0.332 & 0.650 & 0.235 & 0.183 & 0.857 & 0.139 & & \\
\hline & $N$ & 101 & 101 & 101 & 101 & 101 & 101 & 101 & 101 & \\
\hline \multirow[t]{3}{*}{ Sexuality issues } & $\begin{array}{l}\text { Pearson's correlation } \\
\text { coefficient }\end{array}$ & -0.198 & 0.020 & 0.247 & 0.157 & 0.035 & 0.215 & 0.091 & -0.143 & \\
\hline & $\begin{array}{l}\text { Significance probability } \\
\text { (both sides) }\end{array}$ & $0.047^{a}$ & 0.844 & $0.013^{a}$ & 0.118 & 0.729 & $0.031^{\mathrm{a}}$ & 0.363 & 0.155 & \\
\hline & $N$ & 101 & 101 & 101 & 101 & 101 & 101 & 101 & 101 & 101 \\
\hline
\end{tabular}

Analysis to determine the correlation coefficient for each item of distress was performed using Pearson's analysis. The item indexes are yes $=1$, no $=0$, male $=1$, and female $=0$

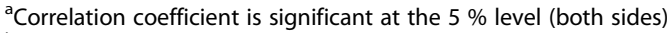

${ }^{\mathrm{b}}$ Correlation coefficient is significant at the $1 \%$ level (both sides)

breast cancer patients is related to their relationships and the adaptation of their partners [38]. Another study showed that not only female cancer patients, but also female partners of male cancer patients, perceived more psychological distress and a lower quality of life than women in healthy couples, although male partners of 
female cancer patients did not differ from their healthy controls [9]. For example, spouses of prostate cancer patients suffered conditions affecting their mood, mental and physical health, and sexual function [10].

In addition, many Japanese women play an important role as a caregiver for their children and parents. As Japan is leaning toward an aging society with fewer children, family care is becoming important and the family function might be decreasing. Female patients need more psychological support from their family members, and social support for cancer patients is also vital.

\section{Spiritual pain}

Male patients were more likely to have spiritual pain than female patients in this study. Previous studies have not mentioned the exact reason for this correlation. In the detailed demographic and clinical characteristics of the patients in Table 1, male patients came to the psycho-oncology outpatient service later than female patients, although there was no statistically significant difference. One of the reasons for this delay might be related to a hesitation by male patients to express their distress. Another is that female patients might react with early stage psychological distress such as anxiety and/or depression after hearing their diagnosis, while male patients might react with a feeling of worthlessness or loneliness included in spiritual pain. In addition, female patients might be influenced by close relationships with family members and male patients might be interested in the meaning of life. Further investigation of the relation between the period when patients come to the outpatient service and the type of distress and individual case scrutiny are needed in the future.

In summary, four items of cancer distress were related to gender differences in this study. Previous studies showed that women suffered from more appearancerelated symptoms and distress resulting from chemotherapy than men [11]. The same findings that female patients were more likely to be suffering from changes in appearance were found in our study. In addition, many previous studies discussed the sexual dysfunction of patients with breast cancer and gynecological cancers [28], and our study also revealed that female patients were more likely to be suffering from sexuality issues than were male patients. However, the novelty of this study is that it clarified the association of family problems with female patients and the association of spiritual pain with male patients.

The present study has several limitations. First, this study was based on consultation cases only in our hospital and the female: male patient ratio was not equivalent. Second, the number of breast cancer patients was large, so it might bring bias to our statistical results, for example, the significant association of gender with sexuality issues. Third, this study was performed by extracting all the items from the patients' medical charts and assessment by several doctors, therefore, a possibility of assessment bias exists.

Although our study has several limitations, some highly suggestive results are seen as helpful for clinical psychooncology practice and for suggesting future studies. In order to elucidate the significance of a specific genderbased support for cancer patients, further research addressing the present study's limitations is necessary.

\section{Conclusions}

There were gender differences in the distress types of cancer patients. Female cancer patients were more likely to be suffering from psycho-social issues such as changes in appearance, family problems, and sexuality issues than were male patients, and male patients were more likely to have spiritual pain. In order to improve the quality of whole cancer care, more intensive intervention by medical professionals and social support is needed from the viewpoint of gender-based medicine and psycho-oncology.

\section{Abbreviations}

HADS: hospital anxiety depression scale; NRS: numeric rating scale.

\section{Competing interests}

The authors declare that they have no competing interests.

\section{Authors' contributions}

AK conceived the study, participated in its design, and performed the statistical analysis. HM and YO participated in its design and coordination and helped draft the manuscript. All authors helped collect the patient data and read and approved the final manuscript.

\section{Authors' information}

AK is Professor and Chair of the Department of Psychosomatic Medicine at Kinki University, Faculty of Medicine. Her research interest focuses on psycho-oncology, gender-specific medicine and psychosomatic medicine. She is a certified doctor of internal medicine, psychosomatic medicine, psychosomatic obstetrics and gynecology, and psycho-oncology, having been certified by each respective Japanese medical society. She was the president of the congress of the Japanese Society of Psycho-oncology held in Osaka in 2013 and the Kinki regional meeting of the Japanese Society of Psychosomatic Medicine held in Osaka in 2006.

\section{Acknowledgements}

We are grateful to the patients who participated in the study and to Michael Likoycheong for proofreading this article.

Received: 14 December 2015 Accepted: 10 March 2016

Published online: 12 April 2016

\section{References}

1. http://www.mhlw.go.jp/toukei/saikin/hw/jinkou/geppo/nengai13/dl/ gaikyou25.pdf. Accessed 13 Feb 2016

2. Hanyda T. Cancer control in Japan. JMAJ. 2012;55(6):501-3. https://www. med.or.jp/english/journal/pdf/2012_06/501_503.pdf. Accessed 13 Feb 2016.

3. Saunders DC, editor. The management of terminal malignant disease. $2 n d$ ed. London: Edward Arnold; 1984. p. 232-41.

4. Maguire R, Kotronoulas $G$, Simpson M, Paterson C. A systematic review of the supportive care needs of women living with and beyond cervical cancer. Gynecol Oncol. 2015;136(3):478-90.

5. Fiszer C, Dolbeault S, Sultan S, Brédart A. Prevalence, intensity, and predictors of the supportive care needs of women diagnosed with breast cancer: a systematic review. Psychooncology. 2014;23(4):361-74. 
6. Pauwels EE, Charlier C, De Bourdeaudhuij I, Lechner L, Van Hoof E. Care needs after primary breast cancer treatment. Survivors' associated sociodemographic and medical characteristics. Psychooncology. 2013;22(1):125-32.

7. Merckaert I, Libert Y, Messin S, Milani M, Slachmuylder JL, Razavi D. Cancer patients' desire for psychological support: prevalence and implications for screening patients' psychological needs. Psychooncology. 2010;19(2):141-9.

8. Faller H, Weis J, Koch U, Brähler E, Härter M, Keller M, et al. Perceived need for psychosocial support depending on emotional distress and mental comorbidity in men and women with cancer. J Psychosom Res. 2016;81:24-30.

9. Hagedoorn M, Buunk BP, Kuijer RG, Wobbes T, Sanderman R. Couples dealing with cancer: role and gender differences regarding psychological distress and quality of life. Psychooncology. 2000;9(3):232-42.

10. Sterba KR, Swartz RJ, Basen-Engquist K, Black PC, Pettaway CA. Long-term quality of life after radical prostatectomy in wives of men in the postoperative adjuvant androgen deprivation trial. Support Care Cancer. 2011;19(8):1117-24.

11. Nozawa K, Shimizu C, Kakimoto M, Mizota Y, Yamamoto S, Takahashi Y, et al. Quantitative assessment of appearance changes and related distress in cancer patients. Psychooncology. 2013;22(9):2140-7.

12. The inquiry of cancer patients in 2010. http://ganseisaku.net/pdf/inquest/ 20110509.pdf. Accessed 13 Feb 2016

13. Zigmond AS, Snaith RP. The hospital anxiety and depression scale. Acta Psychiat Scand. 1983;67:361-70.

14. Murata H. Spiritual pain and its care in patients with terminal cancer: construction of a conceptual framework by philosophical approach. Palliat Support Care. 2003;1(1):15-21.

15. Yoshiuchi K, Kikuchi H. IX Zouketsuki kei shuyou. In: Uchitomi Y, Ogawa A, editors. Seishin Shuyou Gaku. Tokyo: Igaku Shoin; 2011. p. 283.

16. Pan XF, Fei MD, Zhang KY, Fan ZL, Fu FH, Fan JH. Psychopathological profile of women with breast cancer based on the symptom checklist-90-R. Asian Pac J Cancer Prev. 2014;14(11):6579-84.

17. Kugaya A, Akechi T, Okamura H, Mikami I, Uchitomi Y. Correlates of depressed mood in ambulatory head and neck cancer patients. Psychooncology. 1999;8(6):494-9.

18. Ishida K, Ishida J, Kiyoko K. Psychosocial reaction patterns to alopecia in female patients with gynecological cancer undergoing chemotherapy. Asian Pac J Cancer Prev. 2015;16(3):1225-33.

19. Choi EK, Kim IR, Chang O, Kang D, Nam SJ, Lee JE, et al. Impact of chemotherapy-induced alopecia distress on body image, psychosocial well-being, and depression in breast cancer patients. Psychooncology. 2014;23(10):1103-10. doi:10.1002/pon.3531.

20. Monga U, Tan G, Ostermann HJ, Monga TN. Sexuality in head and neck cancer patients. Arch Phys Med Rehabil. 1997;78(3):298-304.

21. Corney RH, Crowther ME, Everett H, Howells A, Shepherd JH. Psychosexual dysfunction in women with gynaecological cancer following radical pelvic surgery. Br J Obstet Gynaecol. 1993;100(1):73-8.

22. Cho J, Choi EK, Kim IR, Im YH, Park YH, Lee S, et al. Development and validation of Chemotherapy-induced Alopecia Distress Scale (CADS) for breast cancer patients. Ann Oncol. 2014;25(2):346-51. doi:10.1093/annonc/mdt476.

23. Deno M, Tashiro M, Miyashita M, Asakage T, Takahashi K, Saito K, et al. Developing the social distress scale for head and neck cancer outpatients in Japan. Palliative Support Care. 2011;9(2):165-72. doi:10.1017/ S1478951511000034

24. Kim IR, Cho J, Choi EK, Kwon IG, Sung YH, Lee JE, et al. Perception, attitudes, preparedness and experience of chemotherapy-induced alopecia among breast cancer patients: a qualitative study. Asian Pac J Cancer Prev. 2012; 13(4):1383-8.

25. Deno M, Tashiro M, Miyashita M, Asakage T, Takahashi K, Saito K, et al. The mediating effects of social support and self-efficacy on the relationship between social distress and emotional distress in head and neck cancer outpatients with facial disfigurement. Psychooncology. 2012;21(2):144-52. doi:10.1002/pon.1877.

26. Hagedoorn M, Molleman E. Facial disfigurement in patients with head and neck cancer: the role of social self-efficacy. Health Psychol. 2006;25(5):643-7.

27. Bober SL, Varela VS. Sexuality in adult cancer survivors: challenges and intervention. J Clin Oncol. 2012;30(30):3712-9. doi:10.1200/JCO.2012.41.7915.

28. Vanlerenberghe $\mathrm{E}$, Sedda AL, Ait-Kaci F. The impact of gynaecological cancers on woman's sexuality and her couple. Bull Cancer. 2015;102(5):454-62.

29. Gilbert E, Ussher JM, Perz J. Sexuality after gynaecological cancer: a review of the material, intrapsychic, and discursive aspects of treatment on women's sexual-wellbeing. Maturitas. 2011;70(1):42-57.
30. Loaring JM, Larkin M, Shaw R, Flowers P. Renegotiating sexual intimacy in the context of altered embodiment: the experiences of women with breast cancer and their male partners following mastectomy and reconstruction. Health Psychol. 2015;34(4):426-36.

31. Loaring JM, Larkin M, Shaw R, Flowers P. Renegotiating sexual intimacy in the context of altered embodiment: the experiences of women with breast cancer and their male partners following mastectomy and reconstruction. J Behav Med. 38(3):565-77. doi:10.1037/hea0000195

32. Levine EG, Silver B. A pilot study: evaluation of a psychosocial program for women with gynecological cancers. J Psychosoc Oncol. 2007;25(3):75-98. doi:10.1300/J077v25n03 05.

33. Zeng YC, Li D, Loke AY. Life after cervical cancer: quality of life among Chinese women. Nurs Health Sci. 2011;13(3):296-302. doi:10.1111/j.1442-2018.2011.00616.x.

34. Wiljer D, Urowitz S, Barbera L, Chivers ML, Quartey NK, Ferguson SE. A qualitative study of an internet-based support group for women with sexual distress due to gynecologic cancer. J Cancer Educ. 2011;26(3):451-8. doi:10.1007/s13187-011-0215-1.

35. McCallum M, Lefebvre M, Jolicoeur L, Maheu C, Lebel S. Sexual health and gynecological cancer: conceptualizing patient needs and overcoming barriers to seeking and accessing services. J Psychosom Obstet Gynaecol. 2012;33(3):135-42. doi:10.3109/0167482X.2012.709291.

36. Ussher JM, Perz J, Gilbert E. Information needs associated with changes to sexual well-being after breast cancer. J Adv Nurs. 2013;69(2):327-37. doi:10. 1111/j.1365-2648.2012.06010.x.

37. Altschuler A, Ramirez M, Grant M, Wendel C, Hornbrook MC, Herrinton L, et al. The influence of husbands' or male partners' support on women's psychosocial adjustment to having an ostomy resulting from colorectal cancer. J Wound Ostomy Continence Nurs. 2009;36(3):299-305.

38. Brusilovskiy E, Mitstifer M, Salzer MS. Perceived partner adaptation and psychosocial outcomes for newly diagnosed stage I and stage II breast cancer patients. J Psychosoc Oncol. 2009;27(1):42-58. doi:10.1080/ 07347330802614774

\section{Submit your next manuscript to BioMed Central and we will help you at every step:}

- We accept pre-submission inquiries

- Our selector tool helps you to find the most relevant journal

- We provide round the clock customer support

- Convenient online submission

- Thorough peer review

- Inclusion in PubMed and all major indexing services

- Maximum visibility for your research

Submit your manuscript at www.biomedcentral.com/submit
Biomed Central 